\title{
Postoperative Inflammation Is an Independent Prognostic Factor in Patients With Thoracic Esophageal Squamous Cell Carcinoma
}

\author{
TAKAHIRO TOYOKAWA ${ }^{1}$, TATSURO TAMURA ${ }^{1}$, KATSUNOBU SAKURAI $^{2}$, NAOSHI KUBO $^{2}$, \\ HIROAKI TANAKA $^{1}$, KAZUYA MUGURUMA ${ }^{1}$, MASAKAZU YASHIRO ${ }^{1}$ and MASAICHI OHIRA ${ }^{1}$ \\ ${ }^{1}$ Department of Gastroenterological Surgery, \\ Osaka City University Graduate School of Medicine, Osaka, Japan; \\ ${ }^{2}$ Department of Gastroenterological Surgery, Osaka City General Hospital, Osaka, Japan
}

\begin{abstract}
Background: The aim of this study was to elucidate the impact of postoperative inflammatory response on prognosis in patients with stage I thoracic esophageal squamous cell carcinoma (ESCC). Materials and Methods: Seventy-five consecutive patients who underwent subtotal esophagectomy for clinical stage I thoracic ESCC were reviewed retrospectively. Maximum serum CRP level $\left(C R P_{\max }\right)$ and white blood cell count $\left(W B C_{\max }\right)$ were evaluated as postoperative inflammatory parameters. Prognostic factors were analyzed using Cox proportional hazards modeling. Results: Optimal cut-off values were $10.7 \mathrm{mg} / \mathrm{dl}$ for $C R P_{\max }$ and $19,700 / \mathrm{mm}^{3}$ for $W B C_{\max }$. On univariate analyses, older age, worse performance status, higher $W B C_{\max }$, and infectious complications were significantly associated with poorer overall survival. Multivariate analysis revealed $W B C_{\max }>19,700 / \mathrm{mm}^{3}$ to be an independent prognostic factor for poorer overall survival ( hazard ratio $=3.356$; 95\% confidence interval $=1.221$-9.220; $p=0.019$ ). Conclusion: $A$ high $W B C_{\max }$ in the early postoperative phase, but not infectious complications, was an independent prognostic factor for poor overall survival in patients with clinical stage I thoracic ESCC.
\end{abstract}

Transthoracic esophagectomy is the mainstay of treatment for local and locoregional disease in thoracic esophageal cancer. Despite significant improvements in the assessment of operative risk, surgical techniques, and perioperative management,

Correspondence to: Takahiro Toyokawa, Department of Gastroenterological Surgery, Osaka City University Graduate School of Medicine 1-4-3 Asahimachi, Abeno-ku, Osaka City, Osaka, 545-8585 Japan. Tel: +81 8666453838, Fax: +81 8666466450, e-mail: t-toyokawa@med.osaka-cu.ac.jp

Key Words: Esophageal cancer, esophagectomy, prognostic factor, inflammation, white blood celI count. esophagectomy for esophageal cancer is the most invasive surgical treatment and is associated with a high morbidity and mortality rates following surgery for gastrointestinal cancer.

Inflammation has been shown to play important roles in the initiation, progression, and metastasis of cancer cells (1). In clinical studies, accumulating evidence has also indicated that the preoperative systemic inflammatory status of patients with cancer affect prognosis (2-4). On the other hand, evidence is lacking concerning the relationship between postoperative inflammatory status and prognosis in such patients. Several studies have demonstrated that postoperative infectious complications are associated with tumor recurrence and worsened prognosis for various malignancies, including esophageal cancer (5-9). In the early postoperative phase, because the systemic inflammatory response is mainly caused not only by infectious complications, but also by surgical stress, both influences should be considered when studying the association between postoperative inflammatory response and prognosis. However, relatively few studies have investigated the relationship between the postoperative inflammatory response (including surgical stress and complications) and prognosis (1012). The significance of postoperative inflammatory response in the early phase after surgery on survival in patients with esophageal cancer thus remains unclear.

In this study, we hypothesized that the postoperative inflammatory response, including surgical stress and infectious complications, would affect long-term outcomes after esophagectomy. The aim of this study was to elucidate the impact of the postoperative inflammatory response for prognosis in patients with stage I thoracic esophageal squamous cell carcinoma (ESCC).

\section{Materials and Methods}

The clinical data of consecutive patients who underwent subtotal esophagectomy with two- or three-field lymphadenectomy and reconstruction using a gastric tube by cervical anastomosis for 
clinical stage I thoracic ESCC at Osaka City University Hospital (Osaka, Japan) between January 2000 and December 2015 were retrospectively reviewed. All patients were diagnosed with ESCC by biopsy before initial treatment. Patients who underwent preoperative chemotherapy and patients with concomitant multiple cancers were excluded. A final total of 75 patients were included. Six patients underwent endoscopic resection resulting in noncurative resection as a prior treatment. Since January $2009,500 \mathrm{mg}$ of methylprednisolone has been administered to patients within 30 min of the start of surgery. Adjuvant chemotherapy was scheduled for patients with pathologically positive lymph node metastasis. This retrospective study was approved by the Ethics Committee at our Institution (approval no. 4067) and was conducted in accordance with the principles of the Declaration of Helsinki.

The pretreatment staging workup in principle included physical examination, laboratory tests, upper gastrointestinal endoscopy, contrast-enhanced computed tomography (CT) between the neck and upper abdomen, and positron-emission tomography-CT as necessary. On the basis of these examinations, tumor stage was assessed according to the seventh edition of the Union for International Cancer Control TNM Classification of Malignant Tumors (13).

Patients with pathological stage I tumors were followed-up every 6 months for 5 years, and annually thereafter, while patients with pathological stage II and III were followed every 4 months for the initial 2 years, every 6 months for the next 3 years, and annually thereafter. On a semiannual basis or on suspicion of recurrence, a clinical history was taken, and a physical examination, routine blood tests, measurement of squamous cell carcinoma antigen, and enhanced CT between the neck and upper abdomen were performed. Positron-emission tomography-CT was conducted as necessary. Recurrence was diagnosed according to the findings of these scheduled examinations. If the patient had not visited the hospital, follow-up information was obtained from telephone calls to the patient, family members, or their referring physician.

The following data were obtained: age, sex, body mass index (BMI), Eastern Cooperative Oncology Group performance status (PS), American Society of Anesthesiology score, tumor location, clinical T-stage, operative procedure, operative time, blood loss, maximum postoperative serum $\mathrm{C}$-reactive protein $\left(\mathrm{CRP}_{\max }\right)$ level and white blood cell $\left(\mathrm{WBC}_{\max }\right)$ count, postoperative infectious complications, tumor size, and pathological findings were evaluated. Postoperative $\mathrm{CRP}_{\max }$ and $\mathrm{WBC}_{\max }$ were defined as the highest levels of these parameters identified between surgery and discharge. The serum CRP level and WBC count were assessed on postoperative days $1,2,3,4,6$ and 8 in principal, and additionally based on the condition of the patient, such as suspicion of a postoperative complication.

Cut-off determination and primary outcomes. To set cut-off values for continuous variables, time-dependent receiver operating characteristic (ROC) curve analyses for 5-year overall survival (OS) as the endpoint were performed, and maximal Youden indices were calculated. All patients were classified into two groups based on these cut-off values.

Statistical analysis. Fisher's exact test or the chi-square test was used for analyzing associations between categorical variables. OS, relapse-free survival (RFS), and cancer-specific survival (CSS) were calculated from the start date of treatment (endoscopic resection or operation) to the date of last follow-up or death, to the confirmed date of recurrence or death, and to the date of last follow-up or death due to esophageal cancer, respectively. Survival rates were calculated by the Kaplan-Meier method, and survival curves were compared with the log-rank test. Uni- and multivariate analyses for OS were conducted with Cox proportional hazards models. Multivariate analysis was performed using variables which in univariate analyses had associations with values of $p<0.05$. Hazard ratios (HRs) and 95\% confidence intervals (CIs) were calculated. Values of $p<0.05$ were considered significant. These statistical analyses were performed using SPSS software (SPSS, Chicago, IL, USA), except for the time-dependent ROC curve analyses that were performed with R-project Software version 3.4.3.

\section{Results}

Time-dependent ROC curve analyses. Time-dependent ROC analyses showed areas under the curve (AUCs) predicting 5year OS were 0.656 for age, 0.679 for BMI, 0.562 for operative time, 0.719 for blood loss, 0.541 for $\mathrm{CRP}_{\max }, 0.750$ for $\mathrm{WBC}_{\max }$, and 0.567 for tumor size. Age of 67 years, BMI of $20.7 \mathrm{~kg} / \mathrm{m}^{2}$, operative time of $634 \mathrm{~min}$, blood loss of $450 \mathrm{ml}, \mathrm{CRP}_{\max }$ of $10.7 \mathrm{mg} / \mathrm{dI}, \mathrm{WBC}_{\max }$ of $19,700 / \mathrm{mm}^{3}$, and tumor size of $20 \mathrm{~mm}$ provided maximal Youden indices, and were therefore selected as the cut-off values.

Clinicopathological characteristics and prognostic factors for OS. Relationships between clinicopathological characteristics and survival are shown in Table I. All patients underwent R0 resection. The median age of patients was 64 years [interquartile range $(\mathrm{IQR})=57.5-69$ years], and the majority were male $(81.3 \%)$. Median BMI was $20.7 \mathrm{~kg} / \mathrm{m}^{2}$ (IQR=19.1$\left.23.0 \mathrm{~kg} / \mathrm{m}^{2}\right)$. The majority of patients had a PS of $0(97.3 \%)$. Operative procedures in thoracic approach consisted of videoassisted thoracic surgery for 65 patients, and open thoracotomy for 10 patients. Median operative time, blood loss, $\mathrm{CRP}_{\max }, \mathrm{WBC}_{\max }$, and tumor size were $561 \mathrm{~min}$ (IQR=507-621 $\mathrm{min}$ ), $420 \mathrm{ml}(\mathrm{IQR}=280-800 \mathrm{ml}), 17.8 \mathrm{mg} / \mathrm{dl}$ $(\mathrm{IQR}=11.8-20.8 \mathrm{mg} / \mathrm{dl}), 13,400 / \mathrm{m}^{3}\left(\mathrm{IQR}=11,700-17,800 / \mathrm{m}^{3}\right)$, and $29 \mathrm{~mm}(\mathrm{IQR}=20-40 \mathrm{~mm})$, respectively.

Postoperative infectious complications were observed in 22 patients (29.3\%), including pneumonia in 13 cases, anastomotic leakage in five cases, bowel perforation in three cases, and wound infection, enteritis, bronchitis, and strangulated ileus in one case each, respectively. No postoperative mortality was encountered.

The results of uni- and multivariate analyses for OS are summarized in Tables I and II. In the univariate analyses, age, PS, $\mathrm{WBC}_{\max }$, and infectious complications were significantly associated with OS. On multivariate analysis for OS using variables with $p<0.05$ on univariate analyses, increasing age $(\mathrm{HR}=2.836 ; 95 \% \mathrm{CI}=1.169-6.883 ; p=0.021)$ and high $\mathrm{WBC}_{\max }(\mathrm{HR}=3.356 ; 95 \% \quad \mathrm{CI}=1.221-9.220$; $p=0.019$ ) were identified as independent prognostic factors. 
Table I. Univariate analyses of prognostic factors for overall survival (OS) of patients with clinical stage I thoracic esophageal squamous cell carcinoma ( $n=75$; 5-year OS for the whole cohort=78.2\%).

\begin{tabular}{|c|c|c|c|c|c|}
\hline \multirow[b]{2}{*}{ Variable } & \multirow[b]{2}{*}{ Subgroup } & \multirow[b]{2}{*}{ 5-Year OS (\%) } & \multicolumn{3}{|c|}{ Univariate } \\
\hline & & & Patients, n (\%) & $\mathrm{HR}(95 \% \mathrm{CI})$ & $p$-Value \\
\hline \multirow[t]{2}{*}{ Age } & $\leq 67$ Years & 86.5 & $48(64.0)$ & 1 & \\
\hline & $>67$ Years & 63.7 & $27(36.0)$ & $2.959(1.287-6.804)$ & 0.011 \\
\hline \multirow[t]{2}{*}{ Gender } & Male & 74.9 & $61(81.3)$ & 1 & \\
\hline & Female & 92.9 & $14(18.7)$ & $0.145(0.019-1.085)$ & 0.060 \\
\hline \multirow[t]{2}{*}{ BMI } & $\leq 20.7 \mathrm{~kg} / \mathrm{m}^{2}$ & 89.9 & $40(53.3)$ & 1 & \\
\hline & $>20.7 \mathrm{~kg} / \mathrm{m}^{2}$ & 65.2 & $35(46.7)$ & $2.037(0.881-4.711)$ & 0.096 \\
\hline \multirow[t]{2}{*}{ Performance status } & 0 & 79.0 & $73(97.3)$ & 1 & \\
\hline & 1 & 50.0 & $2(2.7)$ & $5.290(1.206-23.199)$ & 0.027 \\
\hline \multirow[t]{2}{*}{ ASA } & 1 & 91.7 & $12(16.0)$ & 1 & \\
\hline & 2,3 & 75.2 & $63(84.0)$ & $0.886(0.328-2.396)$ & 0.812 \\
\hline \multirow[t]{3}{*}{ Location } & Upper & 59.7 & $11(14.7)$ & 1 & 0.083 \\
\hline & Middle & 80.7 & $45(60.0)$ & $0.314(0.113-0.870)$ & 0.026 \\
\hline & Lower & 84.2 & $19(25.3)$ & $0.455(0.143-1.442)$ & 0.181 \\
\hline \multirow[t]{2}{*}{ Clinical T stage } & 1a & 79.0 & $15(20.0)$ & 1 & \\
\hline & $1 b$ & 78.3 & $60(80.0)$ & $0.694(0.271-1.776)$ & 0.446 \\
\hline \multirow[t]{2}{*}{ Operative procedure } & VATS & 83.5 & $65(86.7)$ & 1 & \\
\hline & Open & 50.0 & $10(13.3)$ & $1.990(0.770-5.140)$ & 0.155 \\
\hline \multirow[t]{2}{*}{ Operative time } & $\leq 634 \mathrm{~min}$ & 80.6 & $60(80.0)$ & 1 & \\
\hline & $>634 \mathrm{~min}$ & 67.7 & $15(20.0)$ & $1.743(0.701-4.332)$ & 0.232 \\
\hline \multirow[t]{2}{*}{ Blood loss } & $\leq 450 \mathrm{~g}$ & 89.9 & $41(54.7)$ & 1 & \\
\hline & $>450 \mathrm{~g}$ & 64.3 & $34(45.3)$ & $1.930(0.827-4.502)$ & 0.128 \\
\hline \multirow[t]{2}{*}{$\mathrm{CRP}_{\max }$} & $\leq 10.7 \mathrm{mg} / \mathrm{dl}$ & 93.8 & $16(21.3)$ & 1 & \\
\hline & $>10.7 \mathrm{mg} / \mathrm{dl}$ & 74.7 & $59(78.7)$ & $4.630(0.619-34.661)$ & 0.136 \\
\hline \multirow[t]{2}{*}{$\mathrm{WBC}_{\max }$} & $\leq 19,700 / \mathrm{mm}^{3}$ & 85.0 & $62(82.7)$ & 1 & \\
\hline & $>19,700 / \mathrm{mm}^{3}$ & 44.9 & $13(17.3)$ & $3.953(1.662-9.401)$ & 0.002 \\
\hline \multirow[t]{2}{*}{ Infectious complication } & Absent & 85.6 & $53(70.7)$ & 1 & \\
\hline & Present & 61.0 & $22(29.3)$ & $3.014(1.322-6.871)$ & 0.009 \\
\hline \multirow[t]{2}{*}{ Tumor size } & $\leq 20 \mathrm{~mm}$ & 92.3 & $26(34.7)$ & 1 & \\
\hline & $>20 \mathrm{~mm}$ & 71.2 & $49(65.3)$ & $1.272(0.523-3.094)$ & 0.595 \\
\hline \multirow[t]{3}{*}{ Differentiation } & Well & 92.3 & $14(18.7)$ & 1 & 0.821 \\
\hline & Moderate & 77.7 & $36(48.0)$ & $1.371(0.442-4.256)$ & 0.585 \\
\hline & Poor & 70.3 & $25(33.3)$ & $1.099(0.321-3.765)$ & 0.880 \\
\hline \multirow[t]{2}{*}{ Lymphovascular invasion } & Absent & 82.7 & $43(57.3)$ & 1 & \\
\hline & Present & 72.0 & $32(42.7)$ & $1.319(0.580-2.998)$ & 0.508 \\
\hline \multirow[t]{2}{*}{ Pathological T stage } & $1 \mathrm{a}$ & 86.4 & $24(32.0)$ & 1 & \\
\hline & $1 b, 2$ & 74.1 & $51(68.0)$ & $1.239(0.508-3.022)$ & 0.638 \\
\hline \multirow[t]{2}{*}{ Lymph node metastasis } & Absent & 84.5 & $48(64.0)$ & 1 & \\
\hline & Present & 67.1 & $27(36.0)$ & $1.108(0.474-2.587)$ & 0.813 \\
\hline \multirow[t]{2}{*}{ Pathological TNM stage } & I & 84.1 & $47(62.7)$ & 1 & \\
\hline & II, III & 68.5 & $28(37.3)$ & $1.030(0.442-2.400)$ & 0.945 \\
\hline
\end{tabular}

BMI: Body mass index; ASA: American Society of Anesthesiology; VATS: video-assisted thoracic surgery; CRP: C-reactive protein; WBC: white blood cell count; TNM: tumor-node-metastasis; CI: Confidence intervaI; HR: hazard ratio.

Associations between $\mathrm{WBC}_{\max }$ and clinicopathological variables, and frequency of high/low $\mathrm{WBC}_{\max }$ according to postoperative day are listed in Table III and Figure 1, respectively. Higher BMI and infectious complications were significantly associated with $\mathrm{WBC}_{\max }(p=0.001)$.

Survival. Median follow-up for survivors was 91.5 months (IQR=52.5-123.3 months). Two patients were lost to follow- up within 5 years, with 16 months as the shortest follow-up period for survivors. Recurrence was observed in nine cases, with a median time to recurrence of 14 months (range $=8-39$ months). A total of 23 deaths were observed.

Five-year OS, RFS and CSS rates for the entire study population were $78.2 \%, 74.7 \%$, and $91.1 \%$, respectively. Kaplan-Meier survival curves comparing OS, RFS, and CSS according to $\mathrm{WBC}_{\max }$ are shown in Figure 2. For OS and 


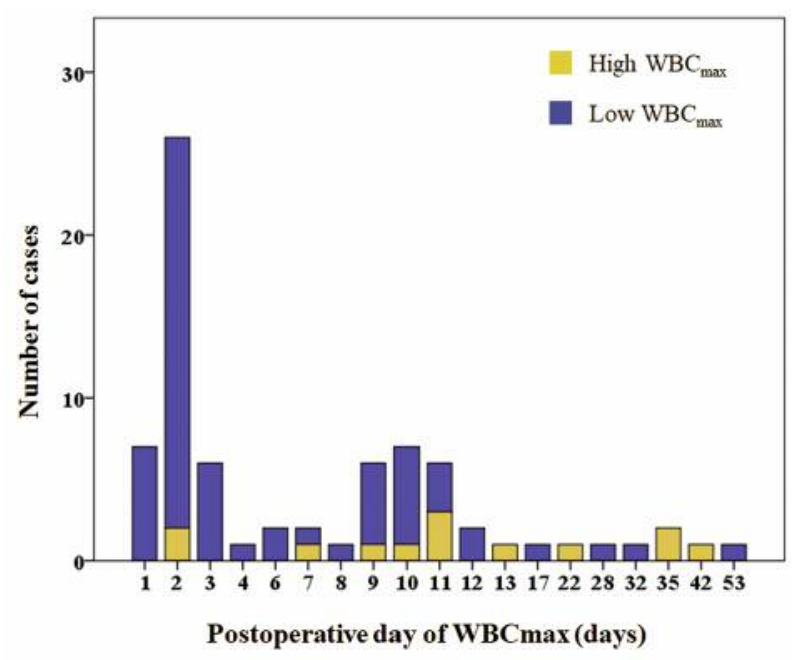

Figure 1. Frequency of high/low maximum postoperative white blood cell count $\left(W B C_{\text {max }}\right)$ according to postoperative days.

Table II. Multivariate analysis of prognostic factors for overall survival of patients with clinical stage I thoracic esophageal squamous cell carcinoma $(n=75)$.

\begin{tabular}{llc}
\hline Variable & \multicolumn{1}{c}{ Multivariate } \\
\cline { 2 - 3 } & \multicolumn{1}{c}{ HR $(95 \% \mathrm{CI})$} & $p$-Value \\
\hline Age & 1 & \\
$\quad \leq 67$ Years & $2.836(1.169-6.883)$ & 0.021 \\
$\quad>67$ Years & 1 & \\
Performance status & $1.752(0.356-8.611)$ & 0.490 \\
$\quad 0$ & 1 & \\
1 & $3.356(1.221-9.220)$ & 0.019 \\
WBC & & \\
$\quad \leq 19,700 / \mathrm{mm}^{3}$ & 1 & 0.325 \\
$\quad>19,700 / \mathrm{mm}^{3}$ & $1.636(0.614-4.363)$ \\
Infectious complication & Absent & \\
Present &
\end{tabular}

CI: Confidence interval; HR: hazard ratio; WBC: White blood cell count.

RFS, but not CSS, 5-year rates were significantly lower in the group with high $\mathrm{WBC}_{\max }(p=0.001, p=0.004$, and $p=0.112$, respectively).

Subgroup analysis. A subgroup analysis according to the presence of infectious complications was conducted. KaplanMeier survival curves comparing $\mathrm{OS}$ based on $\mathrm{WBC}_{\max }$ in patients with and without infectious complications are shown in Figure 3. The OS was significantly lower in the group with
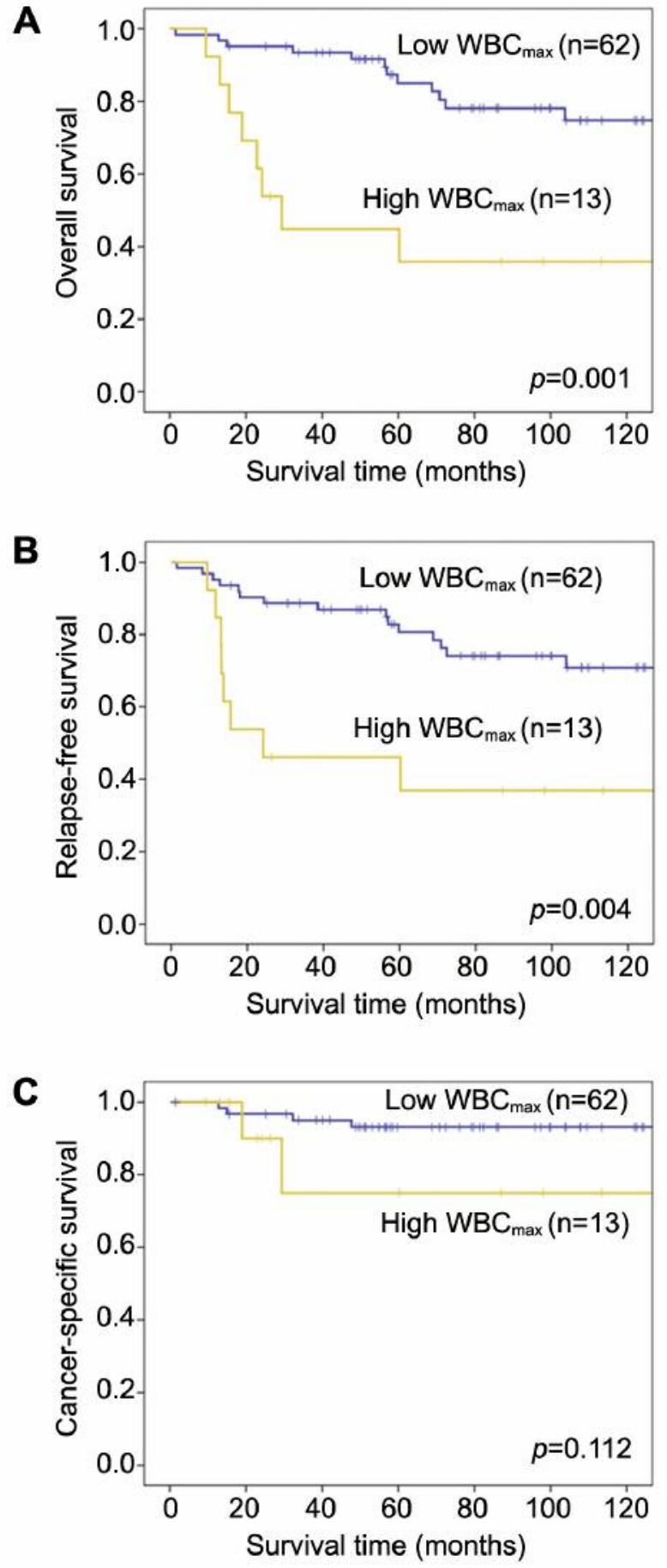

Figure 2. Kaplan-Meier survival curves of overall, relapse-free, cancerspecific survival in patients with clinical stage I thoracic esophageal squamous cell carcinoma according to maximum postoperative white blood cell count $\left(W B C_{\text {max }}\right)$. A: The 3- and 5-year overall survival rates were $93.5 \%$ and $85.0 \%$ in the group with a low $W B C_{\max }$, and $44.9 \%$ and $44.9 \%$ in that with a high $W B C_{\max }(p=0.001) . B:$ The corresponding 3-and 5-year relapse-free survival rates were $88.6 \%$ and $80.6 \%$, and $46.2 \%$ and $46.2 \%$, respectively $(p=0.004)$. $C$ : The corresponding 3-and 5-year cancer-specific survival rates were $95.0 \%$ and $93.1 \%$, and $75.0 \%$ and $75.0 \%$, respectively $(p=0.112)$. 
Table III. Relationships between clinicopathological characteristics and maximum postoperative white blood celI count (WBCmax) in patients with clinical stage I thoracic esophageal squamous cell carcinoma $(n=75)$.

\begin{tabular}{|c|c|c|c|}
\hline Variable & $\begin{array}{l}\text { Low } \mathrm{WBC}_{\max } \\
\quad(\mathrm{n}=62)\end{array}$ & $\begin{array}{l}\text { High } \mathrm{WBC}_{\max } \\
\qquad(\mathrm{n}=13)\end{array}$ & $p$-Value \\
\hline \multicolumn{4}{|l|}{ Age, years } \\
\hline Median (IQR) & $63.5(58.8-69.0)$ & $67(56-72)$ & 0.669 \\
\hline \multicolumn{4}{|l|}{ Gender, n (\%) } \\
\hline Male & $48(77.4)$ & $13(100)$ & \\
\hline Female & $14(22.6)$ & $0(0)$ & $0.110 *$ \\
\hline \multicolumn{4}{|l|}{ BMI, $\mathrm{kg} / \mathrm{m}^{2}$} \\
\hline Median (IQR) & $20.6(18.8-22.3)$ & $23.7(20.1-24.5)$ & ) 0.032 \\
\hline \multicolumn{4}{|c|}{ Performance status, n (\%) } \\
\hline 0 & $61(98.4)$ & $12(92.3)$ & \\
\hline 1 & $1(1.6)$ & $1(7.7)$ & $0.319^{*}$ \\
\hline \multicolumn{4}{|l|}{ ASA, n (\%) } \\
\hline 1 & $12(19.4)$ & $0(0)$ & \\
\hline $2 / 3$ & $50(80.6)$ & $13(100)$ & $0.111 *$ \\
\hline \multicolumn{4}{|l|}{ Location } \\
\hline Upper & $8(12.9)$ & $3(23.1)$ & \\
\hline Middle & $38(61.3)$ & $7(53.8)$ & \\
\hline Lower & $16(25.8)$ & $3(23.1)$ & 0.641 \\
\hline \multicolumn{4}{|c|}{ Clinical T-stage, $\mathrm{n}(\%)$} \\
\hline $1 \mathrm{a}$ & $12(19.4)$ & $3(23.1)$ & \\
\hline $1 \mathrm{~b}$ & $50(80.6)$ & $10(76.9)$ & $0.716^{*}$ \\
\hline \multicolumn{4}{|c|}{ Operative procedure, n (\%) } \\
\hline VATS & $55(88.7)$ & $10(76.9)$ & \\
\hline Open & $7(11.3)$ & $3(23.1)$ & $0.364 *$ \\
\hline \multicolumn{4}{|c|}{ Operative time, $\min$} \\
\hline Median (IQR) & $563(510-620)$ & $537(493-634)$ & 0.823 \\
\hline \multicolumn{4}{|l|}{ Blood loss, $g$} \\
\hline Median (IQR) & $410(256-823)$ & $460(310-930)$ & 0.644 \\
\hline \multicolumn{4}{|l|}{$\mathrm{CRP}_{\max }, \mathrm{mg} / \mathrm{dI}$} \\
\hline Median (IQR) & $16.0(10.9-20.7)$ & $20.7(14.1-24.8)$ & 0.068 \\
\hline \multicolumn{4}{|c|}{$\begin{array}{l}\text { Infectious complication, } \\
\mathrm{n}(\%)\end{array}$} \\
\hline Absent & $49(79.0)$ & $4(30.8)$ & \\
\hline Present & $13(21.0)$ & $9(69.2)$ & $0.001 *$ \\
\hline \multicolumn{4}{|l|}{ Tumor size, mm } \\
\hline Median (IQR) & $26.0(19.5-40.0)$ & $38.0(22.5-51.5)$ & 0.113 \\
\hline \multicolumn{4}{|c|}{ Differentiation, n (\%) } \\
\hline Well & $11(17.7)$ & $3(23.1)$ & \\
\hline Moderate & $31(50.0)$ & $5(38.5)$ & \\
\hline Poor & $20(32.3)$ & $5(38.5)$ & 0.746 \\
\hline \multicolumn{4}{|c|}{$\begin{array}{l}\text { Lymphovascular invasion, } \\
\mathrm{n}(\%)\end{array}$} \\
\hline Absent & $36(58.1)$ & $7(53.8)$ & \\
\hline Present & $26(41.9)$ & $6(46.2)$ & 0.780 \\
\hline \multicolumn{4}{|c|}{ Pathological T stage, n (\%) } \\
\hline 1a & $20(32.3)$ & $4(30.8)$ & \\
\hline $1 b, 2$ & $42(67.7)$ & $9(69.2)$ & $>0.99 *$ \\
\hline \multicolumn{4}{|c|}{ Lymph node metastasis, n (\%) } \\
\hline Absent & $39(62.9)$ & $9(69.2)$ & \\
\hline Present & $23(37.1)$ & $4(30.8)$ & $0.759 *$ \\
\hline \multicolumn{4}{|c|}{$\begin{array}{l}\text { Pathological TNM stage, } \\
\mathrm{n}(\%)\end{array}$} \\
\hline I & $38(61.3)$ & $9(69.2)$ & \\
\hline II, III & $24(38.7)$ & $4(30.8)$ & $0.756^{*}$ \\
\hline \multicolumn{4}{|c|}{ Recurrence, n (\%) } \\
\hline Absent & $56(90.3)$ & $10(76.9)$ & \\
\hline Present & $6(9.7)$ & $3(23.1)$ & $0.183^{*}$ \\
\hline
\end{tabular}

BMI: Body mass index; ASA: American Society of Anesthesiology; VATS: video-assisted thoracic surgery; CRP: C-reactive protein; TNM: tumor-node-metastasis; IQR: interquartile range. *Fisher's exact test.

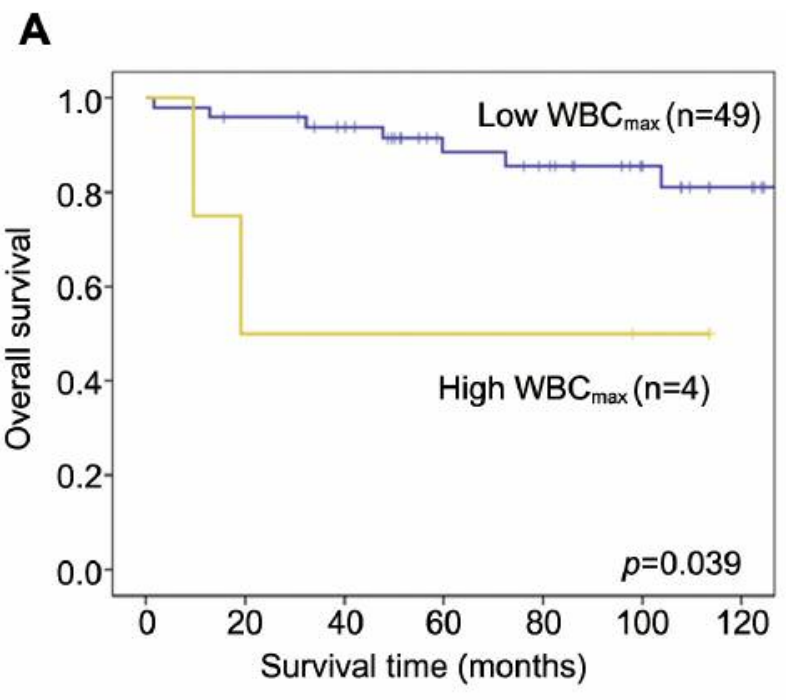

B

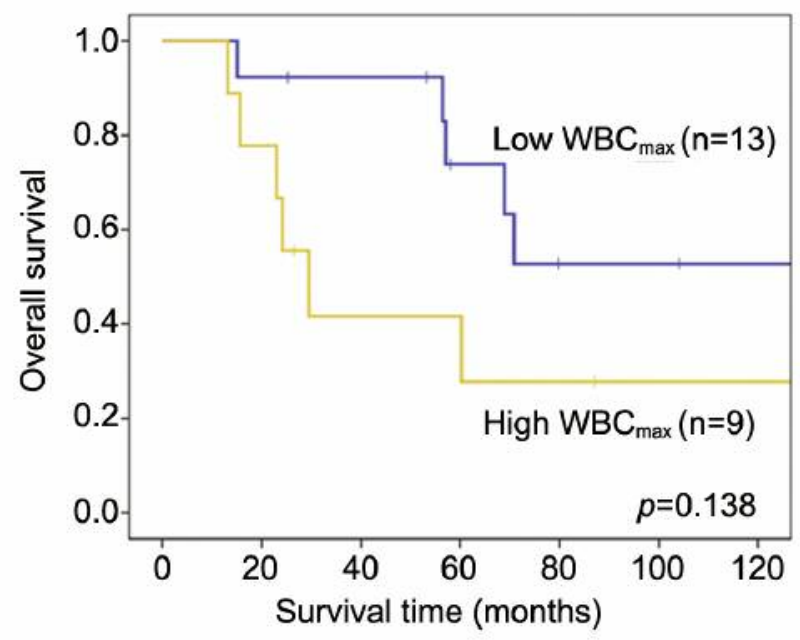

Figure 3. Kaplan-Meier curves of overall survival according to maximum postoperative white blood cell count $\left(W B C_{\text {max }}\right)$ in patients without infectious complications (A: $p=0.039)$ and in patients with infectious complications ( $B: p=0.138$ ).

Table IV. Cause of death in patients with clinical stage I thoracic esophageal squamous cell carcinoma $(n=75)$ according to maximum postoperative white blood cell count $\left(W B C_{\max }\right)$.

\begin{tabular}{lccc}
\hline & $\begin{array}{c}\text { Low } \mathrm{WBC}_{\max } \\
(\mathrm{n}=62), \mathrm{n}(\%)\end{array}$ & $\begin{array}{c}\text { High } \mathrm{WBC}_{\max } \\
(\mathrm{n}=13), \mathrm{n}(\%)\end{array}$ & $p$-Value \\
\hline Total & $15(24.2 \%)$ & $8(61.5 \%)$ & \\
Primary disease & $3(4.8 \%)$ & $2(15.4 \%)$ & $0.205^{*}$ \\
Other disease & $6(9.7 \%)$ & $5(38.5 \%)$ & 0.019 \\
Other cancer & $6(9.7 \%)$ & $1(7.7 \%)$ & $>0.99^{*}$ \\
\hline
\end{tabular}

*Fisher's exact test. 
a high $\mathrm{WBC}_{\max }$ among patients without infectious complications $(p=0.039)$, while no significant difference was seen among patients with infectious complications $(p=0.138)$.

Cause of death. Causes of death according to $\mathrm{WBC}_{\max }$ are shown in Table IV. The proportion of patients who died of other disease was significantly higher in the group with a high $\mathrm{WBC}_{\max }(38.5 \%)$ than in that with a low $\mathrm{WBC}_{\max }$ $(9.7 \%, p=0.019)$, whereas no significant differences were evident in rates of patients who died of primary disease and other cancer.

\section{Discussion}

The present study evaluated the prognostic impact of the postoperative inflammatory response due to surgical stress and infectious complications in 75 patients with clinical stage I thoracic ESCC. We found that a high $\mathrm{WBC}_{\max }$ after esophagectomy was an independent prognostic factor for OS, but infectious complications were not. Our results suggest that a higher $\mathrm{WBC}_{\max }$ in the early phase after surgery affects OS independently of the occurrence of postoperative infectious complications.

Many previous studies have reported that postoperative complications are involved in tumor recurrence and worsened long-term outcomes for various types of cancer $(5,6,8,14)$. Potential explanations for the correlation between postoperative complications and worse prognosis are as follows: i) Some cytokines and growth factors induced by the inflammatory response may promote the proliferation and metastasis of residual cancer cells (1). ii) Host immunosuppression caused by the systemic inflammatory response may lead to a compromised immune response to residual tumor cells (15). In the present study, a high postoperative $\mathrm{WBC}_{\text {max }}$ was significantly associated with poor OS, but not recurrence or CSS, although trends were seen. A plausible explanation for this result is that insufficient residual cancer cells would be present after curative resection, because the study cohort included only patients with clinical stage I thoracic ESCC. On the other hand, our results suggest that a higher inflammatory response in the early postoperative phase worsened the general condition and immunological status, leading to worse OS, which may have been associated with early death within 2 years in our study. Less surgical stress, and postoperative management to prevent and treat complications early are important to improve survival in patients who undergo esophagectomy.

In our study, infectious complications were not an independent prognostic factor, whereas a postoperative high $\mathrm{WBC}_{\text {max }}$, which could reflect the magnitude of the systemic inflammatory response in the early phase after surgery, was. Furthermore, subgroup analysis of patients with an infectious complication revealed worse OS in the group with a high
$\mathrm{WBC}_{\max }$ group than in that with a low $\mathrm{WBC}_{\max }$. These results imply that the magnitude of the systemic inflammatory response due to surgical stress and postoperative infectious complications after esophagectomy is more important for predicting prognosis than the infectious complication itself.

As markers reflecting systemic inflammatory response, we estimated the WBC count and serum CRP level because these are the most commonly evaluated markers of inflammation in postoperative management. Several reports have shown the utility of postoperative serum CRP level as a prognostic factor $(10,11,16-18)$, but few have examined the association between postoperative WBC count and prognosis. Our study is consistent with that of Okumura et al., who showed that prolonged leukocytosis after curative surgery was significantly associated with poorer OS and RFS in advanced gastric cancer (12). In contrast, Saito et al. reported that the WBC count was not significantly associated with RFS, although postoperative elevation of serum CRP ( $\geq 12 \mathrm{mg} / \mathrm{dl}$ ) was an independent prognostic factor in patients with gastric cancer (10). In the present study, postoperative $\mathrm{WBC}_{\max }$ was shown to be an independent prognostic factor for OS, although $\mathrm{CRP}_{\text {max }}$ was not. Unlike previous studies, we determined cut-off values of $\mathrm{WBC}_{\text {max }}$ and $\mathrm{CRP}_{\text {max }}$ based on the results of time-dependent ROC curve analyses, representing a statistical approach. Consequently, WBC count was shown to be superior to serum CRP level in terms of the ability to predict prognosis in our cohort. To the best of our knowledge, this is the first report to show a significant association between postoperative maximum WBC count and OS in patients with esophageal cancer.

Minimally invasive esophagectomy (MIE), such as videoassisted thoracic surgery, have recently gained wide acceptance because this less invasive approach is expected to reduce the surgical stress associated with postoperative systemic inflammation, leading to better prognosis. However, whether MIE is less invasive, and offers better effects in terms of long-term outcome than conventional open esophagectomy remains unclear. A recent meta-analysis demonstrated better OS in an MIE group than in an open esophagectomy group (19). Yamashita et al. reported that MIE not only Ied to a reduced postoperative inflammatory response, but also to significantly more favorable prognosis than open esophagectomy in a propensity score-matched analysis (20). Randomized controlled phase III trials are needed to clarify the superiority of MIE compared with open esophagectomy in terms of long-term outcomes.

The present study has certain limitations that warrant consideration. Firstly, this was a retrospective study conducted at a single institution, and the sample size was small. Secondly, factors that might potentially affect prognosis such as comorbidities could not be excluded. Within these limitations, the present study demonstrated that a high $\mathrm{WBC}_{\max }$ after esophagectomy, but not infectious complications, was an independent prognostic factor for OS. 
Large-scale prospective studies are needed to further validate the utility of postoperative $\mathrm{WBC}_{\max }$ in predicting $\mathrm{OS}$ for patients with esophageal cancer.

\section{Conclusion}

A high $\mathrm{WBC}_{\max }$ in the early phase after surgery was an independent prognostic factor for OS in patients with clinical stage I thoracic ESCC. Estimation of the WBC count is inexpensive and easily available from laboratory data in daily clinical practice. Our results suggest that reducing surgical stress and minimizing infectious complications may improve long-term outcomes for patients undergoing esophagectomy for clinical stage I thoracic ESCC.

\section{Authors' Contributions}

T. Toyokawa analyzed and drafted the article. T. Tamura, K. Sakurai, N. Kubo, H. Tanaka and K. Muguruma participated in data collection and assisted with data interpretation. M. Yashiro and M. Ohira reviewed and revised the article. All Authors read and approved the final article.

\section{Acknowledgements}

The Authors have no conflicts of interest to declare.

\section{References}

1 Candido J and Hagemann T: Cancer-related inflammation. J Clin Immunol 33(Suppl 1): S79-84, 2013. PMID: 23225204. DOI: 10.1007/s10875-012-9847-0

2 Shimada H, Nabeya Y, Okazumi S, Matsubara H, Shiratori T, Aoki T, Sugaya M, Miyazawa Y, Hayashi H, Miyazaki S and Ochiai T: Elevation of preoperative serum $\mathrm{C}$-reactive protein level is related to poor prognosis in esophageal squamous cell carcinoma. J Surg Oncol 83: 248-252, 2003. PMID: 12884238. DOI: $10.1002 /$ jso. 10275

3 Kim DK, Oh SY, Kwon HC, Lee S, Kwon KA, Kim BG, Kim SG, Kim SH, Jang JS, Kim MC, Kim KH, Han JY and Kim HJ: Clinical significances of preoperative serum interleukin- 6 and $\mathrm{C}$-reactive protein level in operable gastric cancer. BMC Cancer 9: 155, 2009. PMID: 19457231. DOI: 10.1186/1471-2407-9-155

4 Jiang X, Hiki N, Nunobe S, Kumagai K, Kubota T, Aikou S, Sano $T$ and Yamaguchi $T$ : Prognostic importance of the inflammation-based Glasgow prognostic score in patients with gastric cancer. Br J Cancer 107: 275-279, 2012. PMID: 22713657. DOI: $10.1038 /$ bjc.2012.262

5 Tokunaga M, Tanizawa Y, Bando E, Kawamura T and Terashima M: Poor survival rate in patients with postoperative intraabdominal infectious complications following curative gastrectomy for gastric cancer. Ann Surg Oncol 20: 1575-1583, 2013. PMID: 23076557. DOI: 10.1245/s10434-012-2720-9

6 Krarup PM, Nordholm-Carstensen A, Jorgensen LN, Harling H: Anastomotic leak increases distant recurrence and long-term mortality after curative resection for colonic cancer: a nationwide cohort study. Ann Surg 259: 930-938, 2014. PMID: 24045445. DOI: 10.1097/SLA.0b013e3182a6f2fc
7 Artinyan A, Orcutt ST, Anaya DA, Richardson P, Chen GJ and Berger DH: Infectious postoperative complications decrease long-term survival in patients undergoing curative surgery for colorectal cancer: A study of 12,075 patients. Ann Surg 261: 497-505, 2015. PMID: 25185465. DOI: 10.1097/SLA.0000 000000000854

8 Markar S, Gronnier C, Duhamel A, Mabrut JY, Bail JP, Carrere N, Lefevre JH, Brigand C, Vaillant JC, Adham M, Msika S, Demartines N, Nakadi IE, Meunier B, Collet D and Mariette C: The impact of severe anastomotic leak on long-term survival and cancer recurrence after surgical resection for esophageal malignancy. Ann Surg 262: 972-980, 2015. PMID: 26469952. DOI: $10.1097 /$ SLA.0000000000001011

9 Yamashita K, Makino T, Miyata H, Miyazaki Y, Takahashi T, Kurokawa Y, Yamasaki M, Nakajima K, Takiguchi S, Mori M and Doki Y: Postoperative infectious complications are associated with adverse oncologic outcomes in esophageal cancer patients undergoing preoperative chemotherapy. Ann Surg Oncol 23: 2106-2114, 2016. PMID: 26753750. DOI: 10.1245/ s10434-015-5045-7

10 Saito T, Kurokawa Y, Miyazaki Y, Makino T, Takahashi T, Yamasaki M, Nakajima K, Takiguchi S, Mori M and Doki Y: Which is a more reliable indicator of survival after gastric cancer surgery: Postoperative complication occurrence or C-reactive protein elevation? J Surg Oncol 112: 894-899, 2015. PMID: 26458724. DOI: $10.1002 /$ jso. 24067

11 Matsuda S, Takeuchi H, Kawakubo H, Fukuda K, Nakamura R, Takahashi T, Wada N, Saikawa Y and Kitagawa Y: Correlation between intense postoperative inflammatory response and survival of esophageal cancer patients who underwent transthoracic esophagectomy. Ann Surg Oncol 22: 4453-4460, 2015. PMID: 25893412. DOI: 10.1245/s10434$015-4557-5$

12 Okumura Y, Hiki N, Kumagai K, Ida S, Nunobe S, Ohashi M and Sano T: Postoperative prolonged inflammatory response as a poor prognostic factor after curative resection for gastric cancer. World J Surg 41: 2611-2618, 2017. PMID: 28451762. DOI: $10.1007 / \mathrm{s} 00268-017-4032-5$

13 Sobin LH, Gospodarowicz MK and Wittekind Ch: TNM Classification of Malignant Tumors, Seventh Edition. Oxford, UK: Wiley-Blackwell, 2009.

14 Saeki H, Tsutsumi S, Tajiri H, Yukaya T, Tsutsumi R, Nishimura S, Nakaji Y, Kudou K, Akiyama S, Kasagi Y, Nakanishi R, Nakashima Y, Sugiyama M, Ohgaki K, Sonoda H, Oki E and Maehara Y: Prognostic significance of postoperative complications after curative resection for patients with esophageal squamous cell carcinoma. Ann Surg 265: 527-533, 2017. PMID: 28169928. DOI: 10.1097/SLA.0000000000001692

15 Roxburgh CS, Horgan PG and McMillan DC: The perioperative immune/inflammatory insult in cancer surgery: Time for intervention? Oncoimmunology 2: e27324, 2013. PMID: 24498571. DOI: 10.4161 /onci.27324

16 McSorley ST, Watt DG, Horgan PG, McMillan DC: Postoperative systemic inflammatory response, complication severity, and survival following surgery for colorectal cancer. Ann Surg Oncol 23: 2832-2840, 2016. PMID: 27016295. DOI: 10.1245/s 10434-016-5204-5

17 Watt DG, McSorley ST, Park JH, Horgan PG and McMillan DC: A postoperative systemic inflammation score predicts short- and long-term outcomes in patients undergoing surgery for colorectal 
cancer. Ann Surg Oncol 24: 1100-9, 2017. PMID: 27822634. DOI: $10.1245 / \mathrm{s} 10434-016-5659-4$

18 Ibuki Y, Hamai Y, Hihara J, Emi M, Taomoto J, Furukawa $\mathrm{T}$, Yamakita I, Kurokawa $\mathrm{T}$ and Okada $\mathrm{M}$ : Role of postoperative c-reactive protein levels in predicting prognosis after surgical treatment of esophageal cancer. World J Surg 41: 1558-1565, 2017. PMID: 28120093. DOI: 10.1007/s00268-017-3900-3

19 Lv L, Hu W, Ren Y, Wei X: Minimally invasive esophagectomy versus open esophagectomy for esophageal cancer: a metaanalysis. Onco Targets Ther 9: 6751-6762, 2016. PMID: 27826201. DOI: $10.2147 /$ OTT.S112105
20 Yamashita K, Watanabe M, Mine S, Toihata T, Fukudome I, Okamura A, Yuda M, Hayami M, Ishizuka N and Imamura Y: Minimally invasive esophagectomy attenuates the postoperative inflammatory response and improves survival compared with open esophagectomy in patients with esophageal cancer: A propensity score matched analysis. Surg Endosc 32: 4443-4450, 2018. PMID: 29644466. DOI: 10.1007/s00464-018-6187-z

Received May 7, 2019

Revised May 17, 2019

Accepted May 20, 2019 